\title{
NETWORKS OF VALUE ADDED TRADE
}

Working Papers 2015
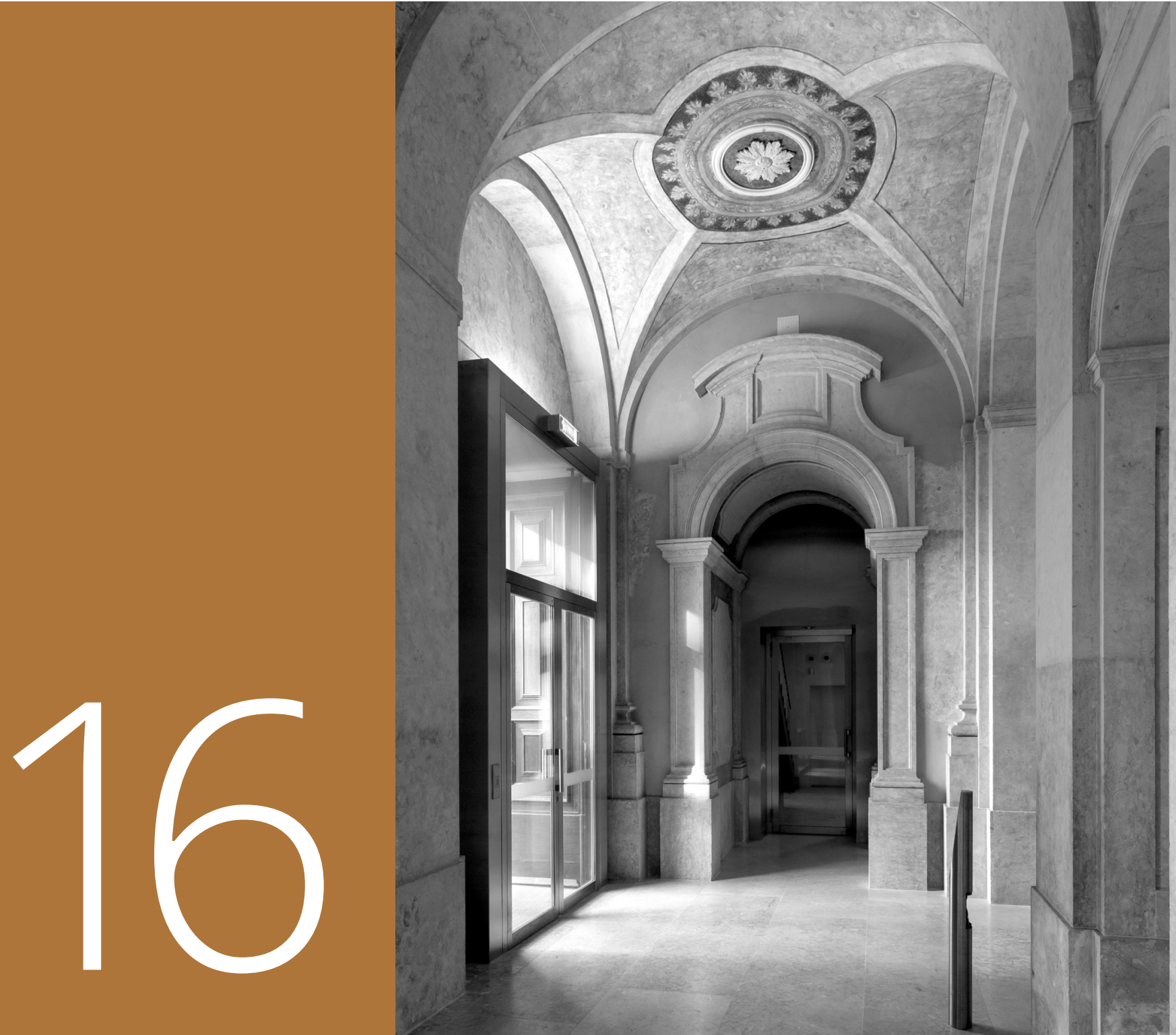



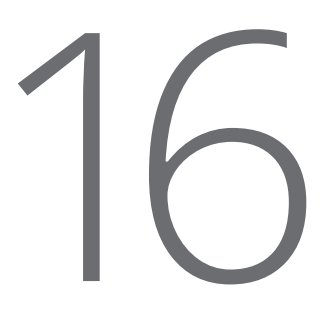

\section{NETWORKS OF VALUE ADDED TRADE}

Working Papers 2015

João Amador | Sónia Cabral

November 2015

The analyses, opinions and findings of these papers represent the views of the authors, they are not necessarily those of the Banco de Portugal or the Eurosystem

Please address correspondence to

Banco de Portugal, Economics and Research Department

Av. Almirante Reis 71, 1150-012 Lisboa, Portugal

T +351213130000 | estudos@bportugal.pt

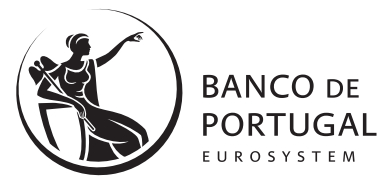

Lisbon, 2015 • www.bportugal.pt 
WORKING PAPERS | Lisbon 2015 • Banco de Portugal Av. Almirante Reis, 71 | 1150-012 Lisboa • www.bportugal.pt • Edition Economics and Research Department • ISBN 978-989-678-389-1 (online) • ISSN 2182-0422 (online) 


\title{
Networks of value added trade
}

\author{
João Amador \\ Banco de Portugal \\ Nova SBE
}

\author{
Sónia Cabral \\ Banco de Portugal
}

October 2015

\begin{abstract}
Global Value Chains (GVCs) became the paradigm for the production of most goods and services around the world. Therefore, linkages among countries can no longer be adequately assessed through standard bilateral gross trade flows and new methods of analysis are needed. In this paper, we apply visualisation tools and measures of network analysis on value-added trade flows in order to understand the nature and dynamics of GVCs. The paper uses data on the bilateral foreign value added in exports from the World Input-Output Database (WIOD) for the period 1995-2011 and, in each period, the GVC is represented as a directed network of nodes (countries) and edges (value added flows). The analysis is extended beyond total trade flows with a view to discussing the distinct roles of goods and services in GVCs. Moreover, the differences between Germany, the US, China and Russia as major suppliers of value added in GVCs are also examined.
\end{abstract}

JEL: F14, F15, C67, D85

Keywords: International trade, Global value chains, Network analysis, Input-output tables, Offshoring, Fragmentation.

Acknowledgements: The opinions expressed in the paper are those of the authors and do not necessarily coincide with those of Banco de Portugal or the Eurosystem. The usual disclaimers apply.

E-mail: jamador@bportugal.pt; scabral@bportugal.pt 


\section{Introduction}

Over the last decades, international trade has grown strongly and its pattern has changed significantly. International production sharing has always been part of international trade as countries import goods to be incorporated in their exports. However, the reduction of transport and communication costs, the acceleration of technological progress and the removal of political and economic barriers to trade greatly increased the opportunities for the international fragmentation of production, i.e., the division of the production chain with different countries specialising in particular stages of production (see Amador and Cabral (2014) for a discussion). Such international fragmentation of production, which has led to the emergence of Global Value Chains (GVCs), poses challenges to policy-makers and it has contributed to deepen the structural interdependence of the world economy in the last decades.

The empirical analysis of GVCs has been focusing on the computation of indicators that break down gross trade flows along sources and destinations of value added, taking advantage of the recent availability of global input-output (I-O) matrices. One of the simplest measures of participation in GVCs is the use of imported inputs to produce goods that are afterwards exported, which is formalised as the foreign value added content of exports (FVAiX) as defined, for instance, in Koopman et al. (2014) and Foster-McGregor and Stehrer (2013). This I-O based measure of fragmentation focuses on the (direct and indirect) import content of exports and it was initially formulated by Hummels et al. (2001), which labelled it "vertical specialisation". The measure captures cases where the production is carried out in at least two countries and the products cross at least twice the international borders.

Given the specific nature of GVCs, these value added flows can be interpreted as the final result of complex linkages established between firms in different sectors and countries over time. In this context, since exports increasingly embody a sizeable share of foreign value added, important questions about the interdependence of economies arise, notably in relation to the impact and propagation of economic shocks. The significant role of specific countries in the functioning of GVCs poses questions regarding the resilience of the world trade system if they are hit by large shocks.

In order to study interconnections between economic agents, economic research has been making progressive use of network analysis tools. These tools were initially used to study social interactions and, more recently, have been applied to research in physics, biology, computer science and others. The appeal of network analysis to study economic relations comes from the ability to identify the whole structure of interactions. Networks assume the interdependence of observations and explore the entire pattern of connections, instead of focusing on the isolated characteristics of each individual element. Therefore, the visualisation of the network structure, using graphs that contain the architecture of nodes linked by edges, allows for the study of the properties 
of individual nodes within the network. In recent years, research on networks has also suggested several measures to examine the large-scale statistical properties of graphs and summarise the main characteristics of the network as a whole. The textbook by Wasserman and Faust (1994) provides a comprehensive discussion of the essential methods used for the analysis of social networks and Newman (2003) reviews developments in the study of complex networks.

Economic research based on social network analysis already covers a wide set of issues. These applications range from labour market outcomes (Calvó-Armengol and Jackson 2004) to systemic risk and financial stability (Acemoglu et al. 2015), the creation of interfirm relationships (Saito et al. 2007), the transmission of microeconomic shocks to aggregate fluctuations (Acemoglu et al. 2012), the functioning of interbank markets (Bargigli et al. 2015), technological regimes and R\&D networks (Orsenigo et al. 2001), and shareholder networks in stock markets (Garlaschelli et al. 2005), among others.

A number of articles have focused on the empirical analysis of international trade interactions from the perspective of complex networks. In the so-called World Trade Web (WTW), each country is a node and the bilateral trade flow between two countries defines an edge between them. Several aspects of the structural and topological properties of the WTW in its undirected/directed and binary/weighted forms were studied by Serrano and Boguñá (2003), Garlaschelli and Loffredo (2004a, 2005), Serrano et al. (2007), Kali and Reyes (2007), Fagiolo et al. (2010) and Fan et al. (2014). The binary WTW was found to be characterised by a relatively high level of clustering (i.e., high probability that two trade partners of a country are themselves connected) and by a disassortative mixing (i.e., countries with many trade partners tend to be linked with countries with few partners), suggesting a hierarchical structure with strong heterogeneity among countries. In addition, international trade literature has also applied network metrics to examine the evolution of total world trade, as in De Benedictis and Tajoli (2011) and De Benedictis et al. (2014), and of trade in specific sectors, as in Akerman and Seim (2014) for arms trade and Amighini and Gorgoni (2014) for auto parts trade.

In this paper, we base on the World Input-Output Database (WIOD) for the period 1995-2011 and make use of basic network analysis tools to describe the characteristics of GVCs. The paper goes beyond total trade in order to asses the specific role played by goods and services as inputs and outputs. At this point it is important to clarify the nature of the exercise performed. The flows of value added in a GVC tend to occur in a sequential way with firms incorporating external value added as they embody intermediate goods in production that is subsequently exported for final consumption or integrated into other products or services. Therefore, the path taken by each unit of value added in the world economy before it reaches the final consumer may be extremely complex and long. In conceptual terms, this path could be identified stepwise in the global I-O matrix. However, given the structure of the matrix, the number of iterations would be huge and the resulting network virtually impossible to 
represent. Instead, economic theory has been focusing on the inverse Leontief matrix to capture the total impact of this iterative process. This is also the approach adopted in this paper, i.e., the network represents the final foreign value added flows and not individual flows in successive stages of the chain. Cerina et al. (2014) and Zhu et al. (2015) also focus on the final value added trade flows but aim at the entire set of country-product linkages. In a different vein, Ferrarini (2013) uses international trade data on products classified as parts and components to quantify vertical trade among countries. The author uses network visualisation tools to map the resulting global network of vertical trade, highlighting the rise of China and the importance of the automotive and electronics sectors in GVCs.

The paper is organised as follows. Section 2 briefly presents the methodology used to decompose value added in trade, the definition of the network of foreign value added in exports and the database used. In section 3 , the evolution of the networks of foreign value added in exports over time is examined using network visualisation tools and through the computation of network measures, with a focus on the differences between goods and services. Finally, section 4 presents some concluding remarks.

\section{Methodology and data}

\subsection{Trade in value added}

This section briefly reviews the methodology underlying the computation of the measure used to asses the participation in GVCs - the foreign value added content in a country's gross exports (FVAiX). The concept of trade in value added links with the fact that both domestic and foreign value added are combined to produce exports, which may be latter embodied in other products or consumed as final goods and services. Nowadays, imports of intermediate products to be embodied in exports are a very important part of the production process, thus gross exports tend to be much larger than their domestic value added component. In addition, the domestic value added included in exports can circulate in the global economy embodied in intermediate products used along the production chain and, in this process, part of it can even return to the domestic economy.

In this context, the measurement of trade in value added implies allocating the value added along the GVC to each producer, thus requiring world I-O tables with information on all bilateral flows of intermediate and final goods and services. The availability of global I-O matrices, where country-sector pairs of inputs are disentangled along country-sector pairs of outputs, has led to several methodological contributions on metrics of trade in value added, i.e., new proxies of participation in GVCs. Several recent articles generalise the concept of "vertical specialisation" of Hummels et al. (2001) and capture different 
dimensions of international flows of value added. The initial contributions were those of Johnson and Noguera (2012), Daudin et al. (2011) and Koopman et al. (2014). The FVAiX is part of this last generation of indicators and it can be computed at a detailed breakdown level.

Next, we follow closely Amador et al. (2015) for a simple presentation of the FVAiX indicator. The most intuitive way to introduce this indicator is to start by defining the domestic value added in exports (DVAiX).

The global Leontief inverse matrix is denoted as $L=(I-A)^{-1}$, with dimension $N C \times N C$, where $N$ stands for the number of sectors and $C$ for the number of countries, and where $I$ is the identity matrix and $A$ is the $N C \times N C$ global I-O matrix. The Leontief inverse matrix is the sum of a converging infinite geometric series with common ratio $A$, that is, $[I-A]^{-1}=$ $\left[I+A+A^{2}+A^{3}+\cdots+A^{x}\right]$, when $x \rightarrow \infty$.

The vector of value added coefficients, i.e., value added created per unit of gross output in country $r$, is denoted by $v^{r}$. This $1 \times N C$ vector contains the value added coefficients for country $r$ and zeros otherwise. Further, exports of country $r$ are written in the vector $e^{r}$, which is of dimension $N C \times 1$ and reports the exports as positive elements and zeros otherwise.

The DVAiX ${ }^{r}$ takes the on-diagonal block in the Leontief inverse for country $r$, pre-multiplies by the value added coefficients in each sector and postmultiplies by the values of exports, that is:

$$
\text { DVAiX }^{r}=v^{r} L^{r r} e^{r}
$$

The FVAiX ${ }^{s r}$ provides the value added directly and indirectly created in the country from which intermediates are imported (source country $s$ ) for production of exports of country $r$ and is calculated in a similar way. It implies pre-multiplying the Leontief inverse by the vector containing the value added coefficients for country $s$ and zeros otherwise, denoted as $v^{s}$, and postmultiplying by the vector of exports of country $r$. In other words, the FVAiX ${ }^{s r}$ basically takes the off-diagonal blocks of the global Leontief inverse for country $r$, pre-multiplies by country $s$ value added coefficients and post-multiplies by the vector of country $r^{\prime}$ exports. Formally, this is written as:

$$
\mathrm{FVAiX}^{s r}=v^{s} L^{s r} e^{r}
$$

Summing up over all partner countries, the total foreign value added embodied in exports of country $r$ is obtained as:

$$
\mathrm{FVAiX}^{r}=\sum_{s, s \neq r} v^{s} L^{s r} e^{r}
$$

Adding the domestic and the foreign value added in exports, as presented in equations 1 and 3, provides the value of total exports of country $r$ in gross terms:

$$
\mathrm{X}^{r}=\mathrm{DVAiX}^{r}+\mathrm{FVAiX}^{r}
$$


The same procedure described in equations 1 to 3 can be applied when the value added content of exports of a particular sector is analysed. In this case only the exports of the selected sector are included in the export vector $e^{r}$.

All value added decompositions computed in this paper were made using the R package decompr (Quast and Kummritz 2015). The analysis is based on the World Input-Output Database (WIOD), which links national supply and use tables with bilateral trade data in goods and services to produce a global I-O table. This database covers 27 European countries and 13 other major world economies and comprises 35 industries, corresponding to a broad NACE classification. The description of the sectors and countries available in the WIOD is included in the Appendix. The sample period starts in 1995 and ends in 2011. Timmer et al. (2015) describe in detail the contents of this database, which includes also data on labour and capital inputs, and illustrate its potential to examine different aspects of the international fragmentation of production.

\subsection{Defining the network}

In this section, we define the network of foreign value added in exports as a directed and unweighted network. The construction of a network requires the identification of a set of nodes or vertices and a criterion for the interactions between them, which will define the edges. In this paper, the nodes are the 40 individual countries that are present in the WIOD $(N=40)$. The criterion for the existence of an edge is set to reflect the importance of a source country $s$ as a supplier of value added for the production of the exports of country $r$. For the purpose of defining what is an important supplier of value in exports, a threshold is set. The choice of the threshold is made in such a way that the resulting network is simple enough to interpret and visualise, while capturing the relevant interrelations between nodes, i.e., the main features of GVCs that are active around the world. The foreign value added threshold was set at 1 percent of total gross exports of the user country. ${ }^{1}$ Hence, the existence of a clear interpretation for the orientation of the edge, i.e., directed from a country whose value added share in another country's exports is larger than the threshold, makes this network directed. More precisely:

$$
\overrightarrow{a_{s r}}= \begin{cases}1 & \text { if } \frac{\text { FVAiX }^{s r}}{\mathrm{X}^{r}}>0.01 \quad \text { for each country } s \neq r=1,2 \ldots N \\ 0 & \text { otherwise }\end{cases}
$$

1. Alternative threshold percentages were tested and the main features of the networks remained qualitatively unchanged. All detailed results are available from the authors upon request. 
where $A=\left[a_{s r}\right]$ is the $N \times N$ connectivity or adjacency matrix.

The analysis in this paper disregards the strength of the edges identified, i.e., the values of the foreign value added shares in exports. Hence, we will only use the binary information contained in the data (unweighted network) and focus on the extensive margin of value added trade among countries.

A very simple but powerful notion in network analysis is the degree of a node. This is simply the number of connections or edges that it has with all other nodes. If the network is directed, every node has two different degrees: indegree and outdegree. The outdegree is the number of outgoing edges and the indegree is the number of incoming edges, that is:

$$
d_{s}^{\text {out }}=\sum_{r=1}^{N} \overrightarrow{a_{s r}} \quad \text { and } \quad d_{s}^{i n}=\sum_{r=1}^{N} \overrightarrow{a_{r s}}
$$

Hence, in this paper, the edges pointing towards a country identify its main suppliers and, conversely, the edges originating from a country reveal its importance as supplier in the GVC.

\section{What can we learn from the networks of value added trade?}

\subsection{The visualisation of the total value added trade network}

Figure 1 displays the network representations of total foreign value added in gross exports in 1995 and 2011. Each country is represented by a circle, with arrows pointing from supplier to receiver of value added. Given the definition presented in equation 5, the scale of an economy interacts with its integration in GVCs to establish its importance within the network. In this setup, a forcedirected layout algorithm is typically used to determine the location of the nodes in the network visualisation. All network graphs in this paper are based on the Harel-Koren fast multi-scale algorithm (Harel and Koren 2002) and are drawn with the use of NodeXL (Hansen et al. 2010). In all network graphs, the size of each node is proportional to its total degree (sum of indegree and outdegree) and the color of the node is mapped to its indegree, with darker shades indicating higher values.

In general, larger countries tend to have bigger nodes and to locate in the centre of the network, mostly because they are important suppliers of value added. Smaller economies tend to locate in the outer layers of the network. These countries are usually placed in intermediate stages of the GVC and act as clients of other countries either at the beginning of the chain (e.g. focused on R\&D and engineering or raw materials) or at the final stages (as assemblers). In addition, some small countries have the darkest nodes in the graph as they use value added from several sources, signalling a strong integration in the network. 


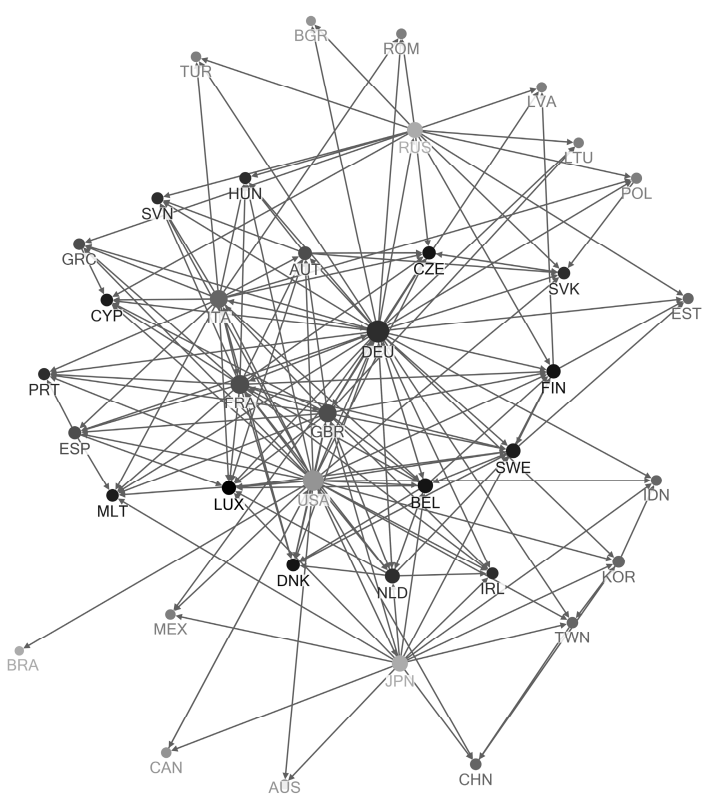

(A) 1995

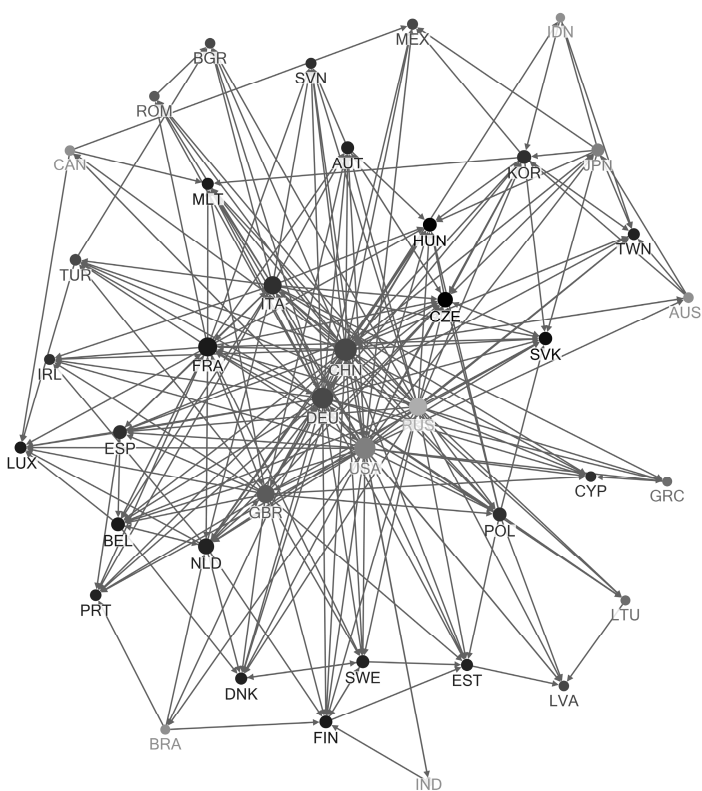

(в) 2011

FiguRE 1: Network graphs of total foreign value added in exports - 1995 and 2001

Notes: The network is directed and the arrows that represent the edges point towards countries whose exports embody more than 1 percent of value added from the source country. The size of each node is proportional to its total degree (sum of indegree and outdegree) and the color of the node is mapped to its indegree, with darker shades indicating higher values. The network graphs are based on the Harel-Koren fast multi-scale algorithm and are drawn with the use of NodeXL (see Hansen et al. (2010) for details), an open-source template for Excel for analysing complex networks (http://nodexl.codeplex.com/). 
The increase in the density of the network from 1995 to 2011, due to a larger number of edges linking the 40 countries in the database, stands out in Figure 1. The flows of foreign value added that are embodied in gross exports became larger, increasing the number of cases where the threshold is surpassed and the respective edges are represented. The position of the nodes takes into consideration their relative importance in the network. In 1995, the countries standing in the core are the large European countries, like Germany, France and the UK, as well as the US. Secondary relations are seen in Asia, centred in Japan as a supplier and linking countries like China, Korea and Taiwan. Other secondary edges locate in Central and Eastern Europe, with Russia supplying value added to several other countries in the region.

In 2011, the network is denser than in 1995 and China joins the inner core. In this period, a closer inspection reveals also that the UK and France moved slightly away from the inner core. This is also the case for Japan, while Germany and the US maintained their central position. A more subtle difference between these two central countries, Germany and the US, is visible considering the shade of their nodes. Even if their nodes are almost of the same size (i.e., similar total degree), the node of Germany is darker than that of the US in both periods. This means that the role of the US is mostly that of a supplier of foreign value added to other countries, while Germany also has some relevance as a client of value added to be embodied in German exports (i.e., higher indegree). Finally, Russia gained importance as a supplier of other countries. This is evident from its bigger but still light-shaded node in 2011, which mostly reflects Russia's role as a major exporter of energy products. These facts are in line with the conclusions of other authors that highlight the progressive transformation of GVCs, evolving from a regional dimension into a truly global network, i.e., the emergence of the so-called "factory world" (see Los et al. (2015) for a discussion).

\subsection{Degree distribution}

The examination of the degree distribution provides some additional insights about the structure of a network. In contrast to a random network, in most real world networks the large majority of nodes has a relatively small degree, while a few nodes have very large degrees. Hence, the degrees of the nodes in most networks are highly right-skewed and their distribution has a long right tail of values that are much higher than the mean. Figure 2 shows the outdegree and indegree marginal cumulative distributions of the networks of foreign value added in exports for 1995 and 2011. The cumulative outdegree (indegree) distribution $P_{k}$ gives the percentage of nodes that have an outdegree (indegree) larger than or equal to $k$, i.e, the probability that the outdegree (indegree) of a node is greater or equal than $k$.

The visual inspection of these distributions confirms that they are markedly right-skewed and became more polarised over time, i.e., with more density 


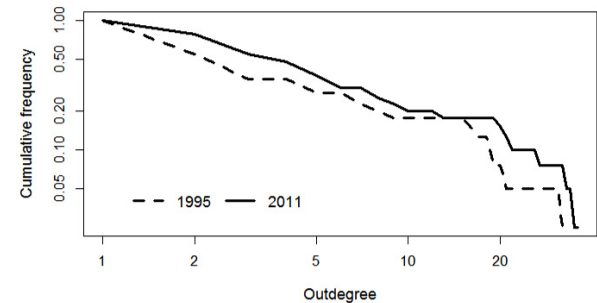

(A) Outdegree

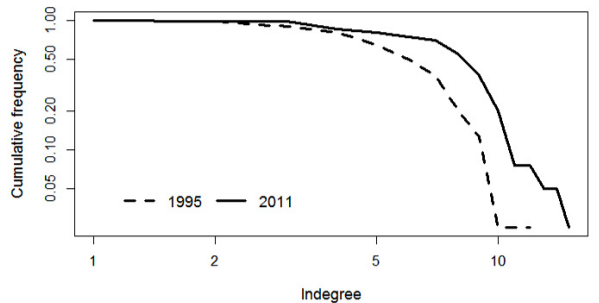

(в) Indegree

Figure 2: Outdegree and indegree marginal cumulative distributions - 1995 and 2001

Notes: The $x$-axis gives the outdegree (indegree) of each country in a log scale. The $y$-axis, also in log scale, gives the probability of finding a country with outdegree (indegree) $\geq x$, that is, the empirical cumulative distribution $P_{x}$.

concentrating around extreme values as the complexity of the network increases. The marginal outdegree distribution is particularly right-skewed as large countries tend to dominate the supply of foreign value added into other countries' exports. For instance, in 1995, 45 percent of the nodes had a null outdegree but that percentage declined to 22.5 percent in 2011, pointing to a deepening of GVCs over time. Another signal of the increase in the complexity of the network is the increase in the percentage of nodes with more outdegrees. In 1995, 17.5 percent of the nodes had outdegree $\geq 8$ and in 2011 that percentage increased to 22.5 percent. In addition, in 2011, 10 percent of the nodes (i.e., 4 countries) had an outdegree $\geq 25$. These countries are China, USA, Germany and Russia and can be labelled as hubs because at least 25 other countries use their value added in the production of exports in a percentage larger than 1.

The same broad features are visible from the marginal indegree distributions, though not so markedly because the distributions are less rightskewed than in the outdegree case. The fact that GVCs became more complex over time is also visible in the increase in the percentage of countries whose exports incorporate foreign value added from many sources. In 1995, 12.5 percent of the nodes had an indegree $\geq 8$ and that percentage increased to 37.5 in 2011.

\subsection{Degree centrality}

Centrality indicators are used to determine how important nodes are in a network. Node degree, which is also designated as degree centrality, is the simplest form of centrality. Figure 3 displays the evolution of indegree and outdegree centralities for the main countries in the GVC network from 1995 
to 2011 and underlines some of the major features observable in the networks of value added trade described above. The most important suppliers of value added throughout the whole period are the US and Germany, countries whose value added is regularly used in the exports of more than 30 other countries. Panel a) of Figure 3 also shows a sharp rise in the outdegree of China since the beginning of the 2000s, accelerating after 2003 and standing as the most important supplier in 2011. In this year, 35 other countries are identified as using Chinese value added in their exports above the defined threshold. Moreover, the role of Russia as a supplier of value added in the world GVCs has also slowly increased since the mid 2000s. Panel b) focuses on other relevant economies, which seem to have lost some of their relative importance as suppliers in the network. The reduction in the outdegree of Japan is clear, while the UK shows an upturn in the latest years of the period, though not compensating the decline that took place after the beginning of the 2000s.

A complementary analysis bases on the identification of the countries that import value added from many sources to embody in their exports. Panel c) of Figure 3 identifies smaller European countries that stand as the most important receivers of foreign value added in the GVC network, i.e., countries with high indegree. The Czech Republic, Hungary and Slovakia progressively increased their importance as clients of foreign value added to be incorporated in exports, which confirms their important role in the intermediate stages of European production chains. Although less markedly, the same evolution is visible for Belgium.

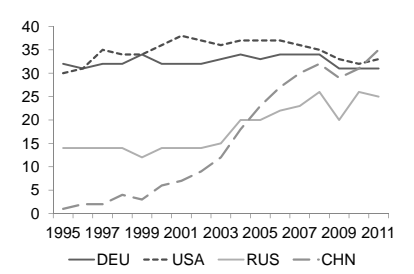

(A) Outdegree centrality

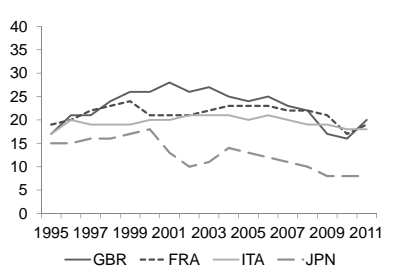

(B) Outdegree centrality

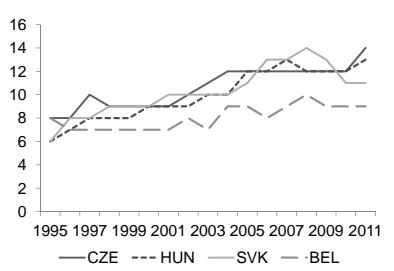

(c) Indegree centrality

Figure 3: Main suppliers and users of foreign value added in exports over time

Notes: The outdegree centrality of a country reflects its relevance as a supplier of foreign value added, while the indegree centrality signals its importance as a user of foreign value added. 


\subsection{The visualisation of the goods and services value added trade networks}

One important dimension of the network of foreign value added in exports relates to the role of the different sectors in the organisation of the GVCs. Not only technology, as defined by the structure I-O tables, imposes a relation between specific sectors, but also choices of firms regarding the organisation of the production process shape the linkages between countries that act as suppliers and users of different types of value added. In this way, we can compare the structures of the networks of foreign value added in exports of certain sectors or of the networks where value added from specific sectors feeds into the exports of different sectors. Although it would be possible to analyse interrelations within all 35 sectors available in the WIOD, in this paper we focus on the differences between goods and services because these broad groups tend to aggregate the most relevant technological differences.

\subsubsection{Goods and services as outputs.}

For each broad sector (goods or services), the edges in the network are set by pairs of countries where the supplier's value added share in the user country's exports of the selected sector is above the threshold. Hence, the reading of the sectoral networks must always take into account that the importance of foreign suppliers of value added is set relative to the user countries' gross exports of goods or of services. In addition, in this subsection, the importance of foreign suppliers bases on value added from all sectors and not just on that originated in the selected broad output sector. Figure 4 represents the networks of total foreign value added in goods and services exports in 2011.

It is clear from the visualisation of these networks that GVCs are more developed and integrated in goods than in services, i.e., there are more edges among countries in the former case. In fact, the representation of the goods exports network in 2011 strongly resembles that of foreign value added in total exports, with China, the US and Germany placed in the inner core as the top 3 suppliers of value added, respectively. In addition, German exports of goods also use foreign value added from more sources than those of the other two main suppliers. The main users of foreign value added in goods exports are again the Czech Republic, Hungary and Slovakia.

As for the services exports network in 2011, the US stands out as the main supplier of foreign value added to be embodied in the services exports of other countries, followed by Germany and then China. Moreover, these three countries are less important as users of foreign value added in their services exports than in their goods exports. In 2011, the country whose services exports use value added from more sources is Denmark, with an indegree of 11 . 


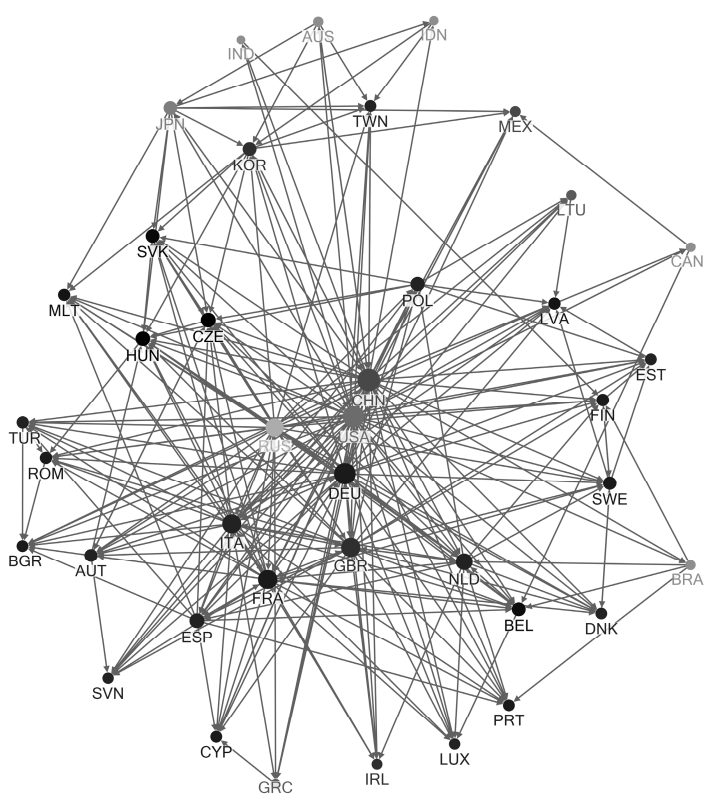

(A) Goods 2011

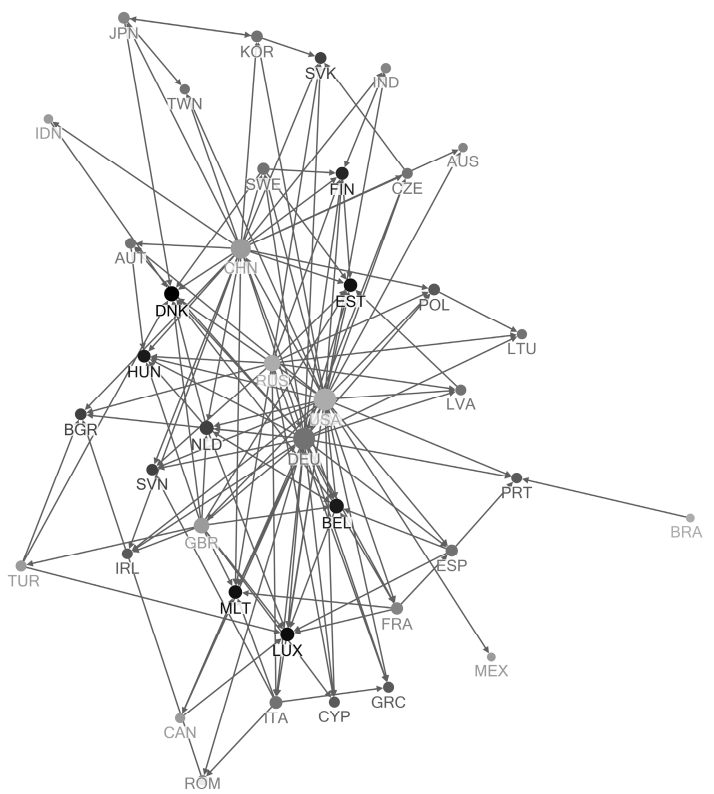

(в) Services 2011

Figure 4: Network graphs of total foreign value added in goods and services exports

Notes: The network is directed and the arrows that represent the edges point towards countries whose exports embody more than 1 percent of value added from the source country. The size of each node is proportional to its total degree (sum of indegree and outdegree) and the color of the node is mapped to its indegree, with darker shades indicating higher values. The network graphs are based on the Harel-Koren fast multi-scale algorithm and are drawn with the use of NodeXL (see Hansen et al. (2010) for details), an open-source template for Excel for analysing complex networks (http://nodexl.codeplex.com/). 
As previously mentioned, the distinct shapes of the goods and services networks depicted in Figure 4 reflect not only the differences in the organisation of GVCs but also the technological differences implicit in the global I-O matrix, i.e., the different number and type of inputs used in the production of goods and of services. Overall, the analysis conveys the message that GVCs presently play a stronger role in goods than in services. Nevertheless, it could be argued that the liberalisation of services trade and the increased demand for services around the world will drive the expansion of GVCs towards more foreign value added of services being embodied in exports of goods or of services. In order to shed some light on these issues, the roles of goods and of services both as inputs and as outputs in GVCs are explicitly considered in the next subsection.

\subsubsection{Goods and services as inputs and outputs.}

The four panels in Figure 5 present the combined roles of goods and of services as both inputs and outputs on value added trade networks in 2011. Comparing panels a) and b), makes it clear that foreign value added of goods is mostly used in GVCs that lead to exports of goods. The network of foreign value added of goods used in services exports is the less dense of the four networks considered. This is not surprising as classical GVCs relate to the trade of parts and components to be embodied in different stages of the manufacturing process, while goods tend to be embodied in services typically as energy sources. In contrast, the comparison of panels c) and d) reveals that foreign inputs of services are embodied both in exports of goods and of services. This result is in line with other studies that highlight the importance of services in GVCs (see, for instance, Amiti and Wei (2005) for a description of the main world trends in outsourcing of services and Francois et al. (2015) for an analysis of the value added trade linkages between services and goods). In fact, the efficient operation of GVCs involves significant inputs of services, like logistics, transportation and other business services, and depends on the availability of the adequate services at low cost. A complementary reading of panels a) and c) states that foreign value added in goods exports comes both from goods and from services inputs, while foreign value added embodied in services exports originates mostly from services inputs (comparison of panels b) and d)). Actually, in recent decades, the sharp progress in information and communication technologies and the dramatic fall in telecommunication costs have enhanced the development of GVCs within the services sector. The network displayed in panel d) confirms the existence of these purely services-based GVCs.

In this setup, it is interesting to assess whether countries that stand as the main users of foreign value-added are the same in the four panels of Figure 5. There are important differences in countries' indegrees that relate with their distinct roles in GVCs. In 2011, the main users of goods foreign value added embodied in goods exports are Hungary and Slovakia with indegrees of 8 . These two Central-Eastern European countries are engaged in classical goods GVCs 
that have been documented in the literature. In this respect, Kaminski and $\mathrm{Ng}$ (2005) offer a detailed analysis of the integration of Central European countries in global, mostly EU-based, networks of production and distribution. In addition, goods exports of Belgium, Taiwan and Malta incorporate goods inputs from 7 other countries. In the sparser network of foreign goods inputs to services exports, the largest indegrees are just 4 for Malta and 3 for Denmark. Regarding services inputs to goods exports, Belgium and Malta include value added from 6 other countries in their exports, while the number for Finland, Luxembourg, Ireland and Hungary is equal to 5. Finally, in the network of services foreign value added in services exports, the two main users in 2011 are Luxembourg and Denmark, embodying foreign inputs from many more sources than the other countries (indegrees of 9 and 8, respectively). Luxembourg and Denmark participate in services GVCs mostly through the use of foreign financial services and transport and other business activities on the production of their significant exports of services. The next group of countries presents indegrees equal to 4 and is composed by the Netherlands, Belgium, Ireland and Hungary.

The main four suppliers of foreign value added in the networks of Figure 5 are Germany, the US, China and Russia, with the exception of the UK, which is the third most important supplier of services inputs to services exports in 2011 (panel d). Even if the countries that act as hubs in these GVCs are the same, their hierarchy is not equal in the four networks. The main suppliers of goods value-added to goods exports are China and Germany, with outdegrees of 31 and 28, respectively, in 2011. The number of countries whose goods exports use goods value-added from Russia and the US is much smaller (19 and 17, respectively). Regarding the sparser network of goods inputs to services exports, the maximum outdegrees are, as expected, much lower. The main suppliers are Russia and Germany with outdegrees of 10, while China and the US have outdegrees of 4 and 3, respectively. The two main suppliers of services foreign value added are the same in the case of goods and of services exports: the US and Germany. However, there is a substantial difference in the relative magnitude of their outdegrees in the two networks depicted in panels c) and d). In the services inputs to goods exports network, the two countries have similar outdegrees ( 24 for the US and 23 for Germany), while, in the services inputs to services exports, the outdegree of the US is much higher than that of Germany (24 and 12, respectively). These differences point to distinct roles played by two of the largest economies on today's geographically dispersed production and the next subsection tries to examine them in more detail. 


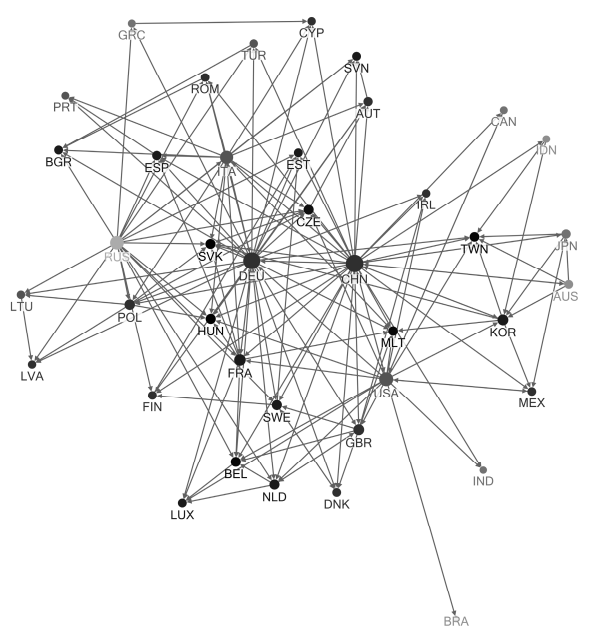

(A) Goods inputs to goods exports

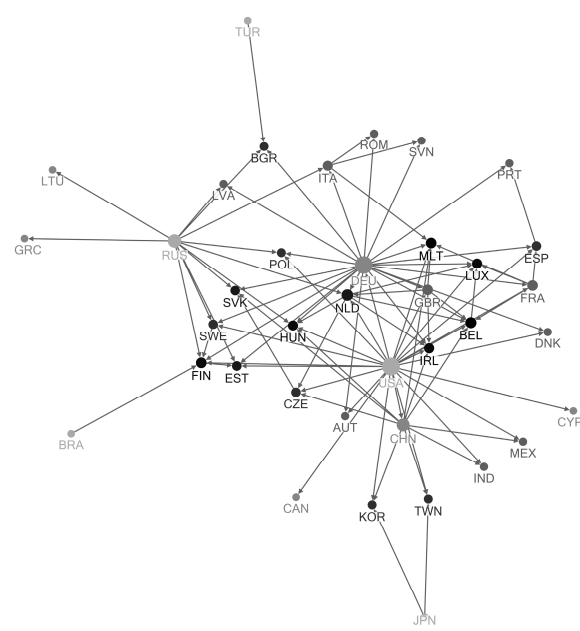

(c) Services inputs to goods exports

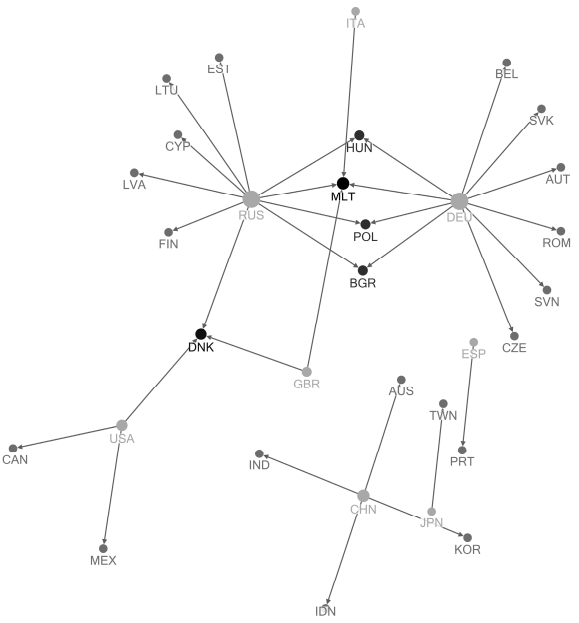

(в) Goods inputs to services exports

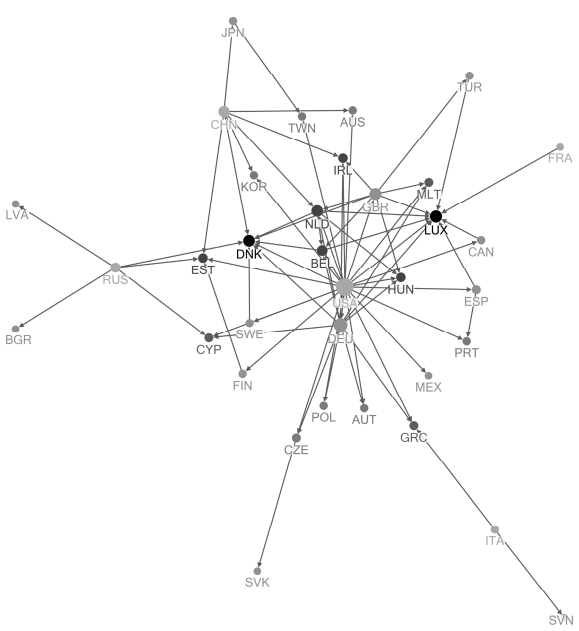

(D) Services inputs to services exports

Figure 5: Network graphs of goods and services foreign value added in goods and services exports in 2011

Notes: The network is directed and the arrows that represent the edges point towards countries whose exports embody more than 1 percent of value added from the source country. The size of each node is proportional to its total degree (sum of indegree and outdegree) and the color of the node is mapped to its indegree, with darker shades indicating higher values. The network graphs are based on the Harel-Koren fast multi-scale algorithm and are drawn with the use of NodeXL (see Hansen et al. (2010) for details), an open-source template for Excel for analysing complex networks (http://nodexl.codeplex.com/). 
3.4.3. Comparing Germany, the US, China and Russia as suppliers of value added.

A complementary analysis to that performed with Figure 5 is to adopt the perspective of the four main suppliers of foreign value added in exports and assess the relevance of each of the goods and services input/output relationships for their outdegrees, i.e., which supply linkages are dominant in terms of their role as hubs on GVCs between 1995 and 2011. Considering each of the four detailed goods and services networks of Figure 5, the evolution of the outdegrees of Germany, US, China and Russia over time is presented in Figure $6 .^{2}$

Panel a) of Figure 6 displays the outdegrees of Germany from 1995 to 2011 in the four detailed networks. The first point to notice is the absence of a major trend in the relative importance of each network, which suggests that Germany established its role in GVCs before 1995. This role is mostly based on the supply of goods value added to be used in other countries' exports of goods. The supply of services to be incorporated in exports of goods of other countries is also relevant. As for the US, there is also no major trend in the relative importance of either goods or services as inputs embodied in exports of goods or services by other countries, signalling a mature GVC participation. Nevertheless, there are some interesting differences relatively to Germany. Although there is a relevant role for goods value added as an input of other countries' exports of goods, the US supplies more services inputs for services exports. Such key role of US services inputs in services exports of other countries points to a type of participation in GVCs that is specific and distinct from that of Germany.

Panel c) of Figure 6 describes the path of China's outdegrees along goods and services dimensions. As expected, the striking element is the sharp increase in the number of outgoing edges after the beginning of the 2000s. The emergence of China as a major world supplier of value added is mostly centred in the goods inputs to goods exports. However, in the latest years, there was also some increase in the number of countries using Chinese services value added in their exports of both goods and services. As for the case of Russia, there is no clear trend in the relative importance of each network in this period but there is some volatility in the outdegrees across time. This volatility reflects the changes in the price of energy goods, which constitute an important element

2. For each country, the sum of the outdegrees obtained in each of the four panels of Figure 5, considering goods and services both as inputs and as outputs, does not match the outdegrees of the total network represented in Figure 1. On the one hand, it is possible that a supplier identified in Figure 1 provides both goods and services value added to be embodied in another country's exports of goods and/or services above the threshold. In the partial networks, these edges are shown separately and each outdegree is counted, while in the total network of Figure 1 they correspond to just one outdegree. On the other hand, in the partial networks the set of inputs is restricted to goods or to services, making it harder that their isolated value added represents a share of total exports of the user country above the defined threshold. 


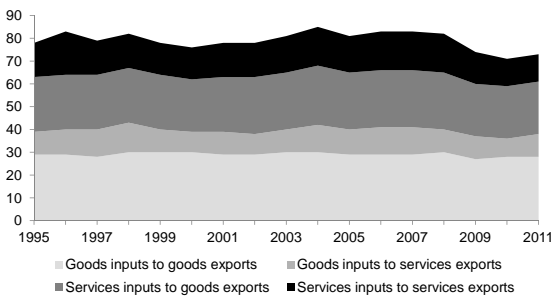

(A) Germany

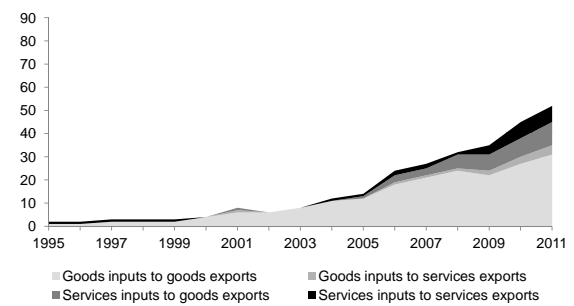

(c) China

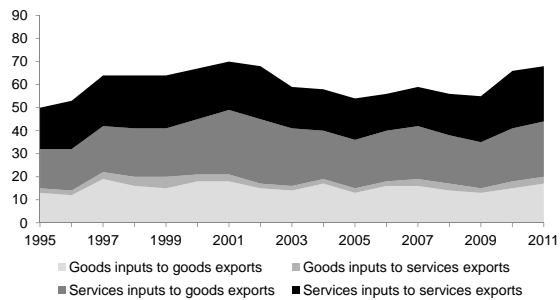

(B) United States

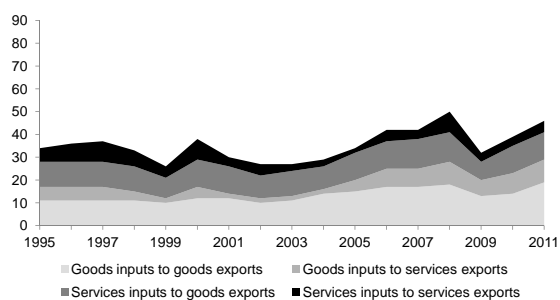

(D) Russia

Figure 6: Main four suppliers of foreign value added in exports over time - goods and services

Notes: In each panel, the outdegrees of the country are those obtained in each of the four networks of subsection 3.4.2, considering goods and services both as inputs and as outputs.

of Russian value added used in other countries' exports. In any case, Russia's role as world supplier of value added mostly relates with goods inputs to goods exports.

\subsection{Aggregate network metrics}

The research on social network analysis has developed a rich set of quantitative network metrics aimed at describing the entire network, i.e., considering not only the position and importance of each node but also the complete set of interactions that establish the key properties of the whole network. Tracking such aggregate metrics over time can also shed light on the dynamics of the patterns of network formation. Figure 7 displays some of these macro measures for the networks of total foreign value added in total, goods and services exports over time. In line with the analysis of the previous sections, the results of the aggregate metrics are broadly similar for total and goods exports, while the measures computed for the network of foreign value added in services exports show a distinct behaviour.

A very simple aggregate metric is the average degree of the network, which measures its average connectivity (panel a). From 1995 to 2011, there was an increase in average degree, which means that, on average, each country 
has a larger number of client/supplier relations. Therefore, over this period, the GVC network became more complex and strongly connected, as trade in intermediates among countries intensified. This result is much stronger for total trade and goods than for services networks.

The geodesic distance is the length of the shortest path between two nodes and the average geodesic distance or characteristic path length is simply its average over all nodes. It is a measure of how close nodes are to each other in a network and could be seen as a measure of economic integration. The average geodesic distances depicted in panel b) have relatively low values, similar to those of comparable random networks. In addition, a decreasing trend is evident for total and goods networks, in spite of a slight upturn during the global crisis, meaning that countries are becoming more integrated.

The prime node-specific network metrics are the centrality measures that aim at identifying the most important nodes in a network. Several definitions of centrality exist in the literature in line with the distinct meanings of importance of a node. As discussed in Jackson (2008), node centrality measures can be broadly categorised into four groups: degree (how connected a node is, as used in the previous sections); closeness (how easily a node can reach other nodes); betweenness (how important a node is for connecting other nodes); and neighbours' characteristics (how important a node's neighbours are). In this latter class of centrality measures, the centrality of a node is recursively related to the centralities of the nodes it is connected to, i.e., a node's importance depends on how important its neighbours are. This category includes the measure of eigenvector centrality used herein, among others.

Centralisation is an aggregate metric that characterises how a network is centred on around one or a few important nodes by examining the differences in centrality between the most central node in a network and all others. Higher levels of centralisation indicate a more concentrated network structure, dominated by one or a few very central nodes. In this sense, a very centralised network is less resilient to shocks as it can fail if such important nodes are not present. The centralisation measures of the three value added networks are very high but decreased over time, specially for total trade and goods networks (panel c). This means that node eigenvector centrality scores have become relatively closer over time. Therefore, while a set of major economies maintained their core positions in the network over the whole the period, their influence has declined as other important players entered the GVC.

With directed networks, it is also relevant to examine the extent to which ties are reciprocated, as a predominance of asymmetric relations points to a hierarchical structure. Panel d) of Figure 7 presents the measure of reciprocity of Garlaschelli and Loffredo (2004b), which computes the proportion of edges that are reciprocated, while accounting for the density of the network. Hence, this measure is appropriate to examine the evolution of reciprocity of a network with time-varying density. The services network shows an antireciprocal behaviour over the whole period, as the probability of occurring mutual links 


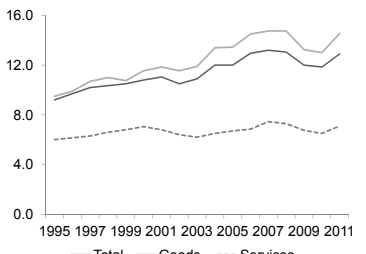

(A) Average degree

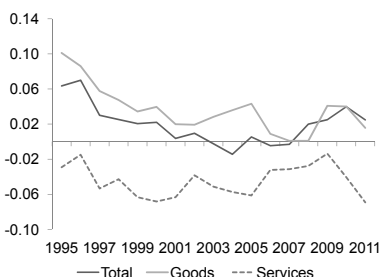

(D) Reciprocity correlation

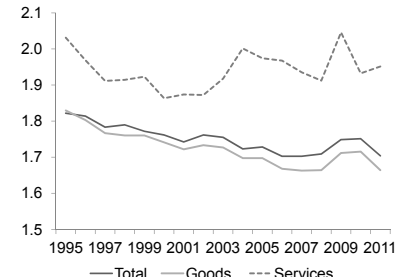

(B) Average geodesic distance

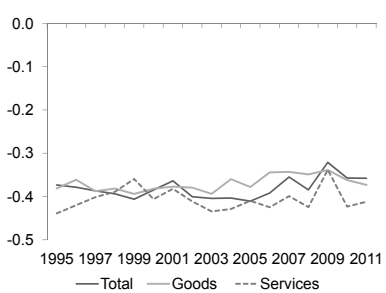

(E) Degree assortativity

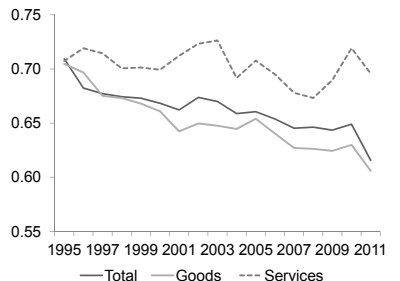

(c) Centralisation of eigenvector centrality

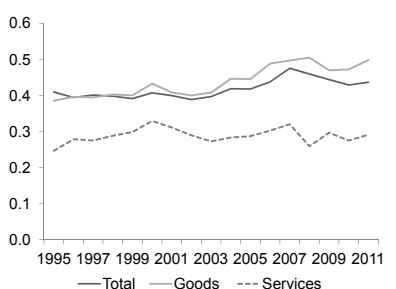

(F) Global clustering coefficient

Figure 7: Aggregate network metrics over time

Notes: Network metrics were computed using the $\mathrm{R}$ packages statnet (Handcock et al. 2003) and igraph (Csardi and Nepusz 2006). With the exception of the reciprocity correlation coefficient, all aggregate network measures were computed ignoring the directionality of the edges.

is smaller than in a random network. Total trade and goods networks are reciprocal networks in most periods but the values obtained are very low. However, for these two networks, there is some increase in the proportion of mutual connections in the last years. This increase in the percentage of two-way value added flows within the network suggests some deepening of GVCs with some countries acting both as clients and suppliers of each other.

The pattern of connectivity among nodes of varying degrees also affects the interaction dynamics of the network. If the high-degree nodes in a network tend to be connected with other high-degree nodes, then the network is said to be assortative or to show assortative mixing. On the contrary, the network is said to be disassortative if the nodes with many connections tend to be attached to other nodes with few connections. Degree assortativity is a network-level measure which quantifies the tendency of nodes to link with nodes with similar degrees, i.e., it refers to the correlation between the degrees of adjacent nodes. Starting from the work of Serrano and Boguñá (2003), most empirical studies on international trade networks have found that they are characterised by a disassortative mixing, as highly connected countries tend to connect to poorly connected countries. The results obtained for the value added networks included in panel e) also show such a disassortative pattern. This feature reflects the 
existence of a few big and central countries that act as hubs and its economic interpretation can be linked with the discussion on core-periphery relationships.

Another important aspect of networks is how tightly clustered they are. There is a variety of concepts that measure how cohesive or closely knit a network is. The global clustering coefficient or weak transitivity is defined as the probability of two nodes being connected if they share a mutual neighbour and gives an overall indication of clustering in the whole network. For total trade and goods value added networks, there was a slight increase in the clustering coefficient until 2008 and some decline afterwards in the former (panel f). However, the clustering values are much higher than those corresponding to a random network of the same size, which suggests the presence of a hierarchical structure and a tendency of countries to group together around some influential players. ${ }^{3}$ The values of the global clustering coefficient are always smaller in the value added network of services and its path is more stable over time.

In summary, the analysis of these aggregate metrics shows that the foreign value added networks are very centralised and asymmetric networks, where a few large economies act as the main suppliers of value added, thus, creating their areas of influence. Overall, these results are in line with those obtained from studies of the WTW in its binary form, which was found to have smallworld properties (high clustering coefficient and low average geodesic distance) and a hierarchical structure with a disassortative pattern. ${ }^{4}$ Over time, value added trade networks became more complex and intensely connected and their hierarchical structure has been somewhat moderated with the entrance of new players and the establishment of new value added linkages among them.

\section{Final remarks}

Global Value Chains (GVCs) have deeply changed the paradigm of world production and cannot be perfectly understood under the classical concept of comparative advantages applied to broad sectors and countries. Instead, GVCs are mostly about combining value added from different sources. Their effects span over multiple dimensions, namely trade flows, productivity and labour market developments. GVCs also have significant policy implications, changing the way policy-makers interpret trade policies, exchange rate fluctuations

3. We choose to represent the global clustering coefficient over time in panel f) of Figure 7 because it is less sensitive to the inclusion of low degree nodes than the average local clustering coefficient. In our case, the average local clustering coefficient is higher than the global clustering coefficient in all networks considered and both are higher than the clustering coefficient of an equivalent random network.

4. Small-world networks, according to Watts and Strogatz (1998), are a class of networks that are highly clustered, like regular networks, and have small characteristic path lengths, like random graphs. For a discussion of the small-world properties of a network, see Humphries and Gurney (2008) and Telesford et al. (2011). 
and external competitiveness. The correct understanding of the nature and dynamics of GVCs is crucial to reap the benefits from international trade and to assess the role, if any, that economic policy can play in shaping their evolution.

The expansion of GVCs requires new tools for evaluating the linkages among countries, which can no longer be adequately appraised by bilateral gross trade flows. This paper makes use of standard tools of network analysis to examine the evolution of value added trade linkages between countries in the period 1995-2011. More specifically, we focus on the concept of foreign value added in exports and the GVC is represented as a directed network of nodes (countries) and edges (value added flows between them). The analysis starts with the network of foreign value added in total exports, continues with the roles of goods and of services as both inputs and outputs in GVCs, and then summarises the main differences between Germany, the US, China and Russia as hubs in value added trade. Finally, several aggregate network metrics are computed and the evolution of the key properties of the networks of foreign value added in total, goods and services exports are discussed.

As the empirical research on the international fragmentation of production expands, the analysis of the networks of foreign value added in exports is a complementary tool for understanding GVCs. Not surprisingly, several results obtained from our network analysis of value added trade confirm results of other studies. Larger countries play a vital role and the regional dimension of GVCs is still dominant, though it is progressively giving way to a more global network. The network of foreign value added in goods exports is denser than that of services exports, but some purely services-based GVCs are visible.

At country-level, Germany and the US maintain a robust participation in GVCs over the whole period, but with meaningful differences between them. Germany mostly bases its role as a major supplier of goods value added to be used in other countries' exports of goods, while the US supplies more services inputs to services exports. In addition, Germany also has some relevance as a client of value added to be embodied in German exports, while the US mostly acts as a supplier of value added to other countries. The rising importance of China as a supplier of value added is a clear result of the analysis. The emergence of China is mostly centred in the supply of goods inputs to the exports of goods of other countries.

The analysis of aggregate network metrics reveals that GVCs are very centralised and asymmetric networks, with a few large economies acting as hubs. These networks are also characterised by small-world properties, showing a hierarchical structure with a disassortative pattern. Over time, with the integration of new countries in GVCs, the networks of value added trade became denser, more complex and intensely connected. However, all in all, there is still room to expand and deepen the networks of value added trade in the global economy, both through the stronger integration of peripheral economies and the development of linkages in the services sector. 
In spite of the intense research over the last decades, the mapping and measurement of GVCs is still incomplete and the use of tools of network analysis may bring valuable results. For example, as discussed in Carvalho (2014), a network perspective of production linkages offers important insights on the propagation of shocks and on the origins of aggregate fluctuations. An extension of this literature to account for value added trade flows can be useful to examine the international transmission of shocks and the synchronisation of business cycles across countries. In fact, the relevance of network analysis to understand the structure and organisation of world production as GVCs is great and the existing research is still in its infancy. Network analysis and its metrics can help to capture the heterogeneity of the firms, sectors and/or countries participating in GVCs, accounting for their direct and indirect linkages, and to explore the complexity of the whole structure of interactions. The rich and diversified set of measures in network theory and the ability to build models on global supply chains that incorporate these features are promising avenues for future research. 


\section{References}

Acemoglu, Daron, Vasco M. Carvalho, Asuman Ozdaglar, and Alireza Tahbaz-Salehi (2012). "The Network Origins of Aggregate Fluctuations." Econometrica, 80(5), 1977-2016.

Acemoglu, Daron, Asuman Ozdaglar, and Alireza Tahbaz-Salehi (2015). "Systemic Risk and Stability in Financial Networks." American Economic Review, 105(2), 564-608.

Akerman, Anders and Anna Larsson Seim (2014). "The global arms trade network 1950-2007." Journal of Comparative Economics, 42(3), 535-551.

Amador, João and Sónia Cabral (2014). "Global Value Chains: A Survey of Drivers and Measures." Journal of Economic Surveys, Forthcoming.

Amador, João, Rita Cappariello, and Robert Stehrer (2015). "Global Value Chains: A View from the Euro Area." Asian Economic Journal, 29(2), 99120.

Amighini, Alessia and Sara Gorgoni (2014). "The International Reorganisation of Auto Production." The World Economy, 37(7), 923-952.

Amiti, Mary and Shang-Jin Wei (2005). "Fear of service outsourcing: Is it justified?" Economic Policy, 20(42), 308-347.

Bargigli, L., G. di Iasio, L. Infante, F. Lillo, and F. Pierobon (2015). "The multiplex structure of interbank networks." Quantitative Finance, 15(4), 673691.

Calvó-Armengol, Antoni and Matthew O. Jackson (2004). "The Effects of Social Networks on Employment and Inequality." American Economic Review, $94(3), 426-454$.

Carvalho, Vasco M. (2014). "From Micro to Macro via Production Networks." Journal of Economic Perspectives, 28(4), 23-48.

Cerina, Federica, Zhen Zhu, Alessandro Chessa, and Massimo Riccaboni (2014). "World Input-Output Network." Working Papers 6/2014, IMT Institute for Advanced Studies Lucca.

Csardi, Gabor and Tamas Nepusz (2006). "The igraph software package for complex network research." InterJournal, Complex Systems, 1695.

Daudin, Guillaume, Christine Rifflart, and Danielle Schweisguth (2011). "Who produces for whom in the world economy?" Canadian Journal of Economics, 44(4), 1403-1437.

De Benedictis, Luca, Silvia Nenci, Gianluca Santoni, Lucia Tajoli, and Claudio Vicarelli (2014). "Network Analysis of World Trade using the BACI-CEPII Dataset." Global Economy Journal, 14(3-4), 287-343.

De Benedictis, Luca and Lucia Tajoli (2011). "The World Trade Network." The World Economy, 34(8), 1417-1454.

Fagiolo, Giorgio, Javier Reyes, and Stefano Schiavo (2010). "The evolution of the world trade web: a weighted-network analysis." Journal of Evolutionary Economics, 20(4), 479-514. 
Fan, Ying, Suting Ren, Hongbo Cai, and Xuefeng Cui (2014). "The state's role and position in international trade: A complex network perspective." Economic Modelling, 39, 71-81.

Ferrarini, Benno (2013). "Vertical Trade Maps." Asian Economic Journal, $27(2), 105-123$.

Foster-McGregor, Neil and Robert Stehrer (2013). "Value Added Content of Trade: A Comprehensive Approach." Economics Letters, 120(2), 354-357.

Francois, Joseph, Miriam Manchin, and Patrick Tomberger (2015). "Services Linkages and the Value Added Content of Trade." The World Economy, Forthcoming.

Garlaschelli, Diego, Stefano Battiston, Maurizio Castri, Vito D.P. Servedio, and Guido Caldarelli (2005). "The scale-free topology of market investments." Physica A: Statistical Mechanics and its Applications, 350(2), 491-499.

Garlaschelli, Diego and Maria I. Loffredo (2004a). "Fitness-Dependent Topological Properties of the World Trade Web." Physical Review Letters, 93, 188701.

Garlaschelli, Diego and Maria I. Loffredo (2004b). "Patterns of Link Reciprocity in Directed Networks." Physycal Review Letters, 93, 268701.

Garlaschelli, Diego and Maria I. Loffredo (2005). "Structure and evolution of the world trade network." Physica A: Statistical Mechanics and its Applications, 355(1), 138-144.

Handcock, Mark S., David R. Hunter, Carter T. Butts, Steven M. Goodreau, and Martina Morris (2003). statnet: Software tools for the Statistical Modeling of Network Data. Seattle, WA, URL http://statnetproject.org.

Hansen, Derek, Ben Shneiderman, and Marc A. Smith (2010). Analyzing Social Media Networks with NodeXL: Insights from a Connected World. Morgan Kaufmann Publishers Inc., San Francisco, CA, USA, URL http: //nodexl. codeplex.com.

Harel, David and Yehuda Koren (2002). "A Fast Multi-Scale Method for Drawing Large Graphs." Journal of Graph Algorithms and Applications, 6, 179-202.

Hummels, David, Jun Ishii, and Kei-Mu Yi (2001). "The Nature and Growth of Vertical Specialization in World Trade." Journal of International Economics, 54(1), 75-96.

Humphries, Mark D. and Kevin Gurney (2008). "Network 'Small-World-Ness': A Quantitative Method for Determining Canonical Network Equivalence." PLoS ONE, 3(4), e0002051.

Jackson, Matthew O. (2008). Social and Economic Networks. Princeton University Press, Princeton, NJ, USA.

Johnson, Robert C. and Guillermo Noguera (2012). "Accounting for Intermediates: Production Sharing and Trade in Value Added." Journal of International Economics, 86(2), 224-236.

Kali, Raja and Javier Reyes (2007). "The architecture of globalization: a network approach to international economic integration." Journal of 
International Business Studies, 38(4), 595-620.

Kaminski, Bartlomiej and Francis Ng (2005). "Production disintegration and integration of Central Europe into global markets." International Review of Economics \& Finance, 14(3), 377-390.

Koopman, Robert, Zhi Wang, and Shang-Jin Wei (2014). "Tracing Value-added and Double Counting in Gross Exports." American Economic Review, 104(2), 459-494.

Los, Bart, Marcel P. Timmer, and Gaaitzen J. de Vries (2015). "How Global are Global Value Chains? A New Approach to Measure International Fragmentation." Journal of Regional Science, 55(1), 66-92.

Newman, M. E. J. (2003). "The Structure and Function of Complex Networks." SIAM Review, 45(2), 167-256.

Orsenigo, L., F. Pammolli, and Massimo Riccaboni (2001). "Technological change and network dynamics: Lessons from the pharmaceutical industry." Research Policy, 30(3), 485-508.

Quast, Bastiaan and Victor Kummritz (2015). "decompr: Global Value Chain decomposition in R." CTEI Working Papers, (1).

Saito, Yukiko Umeno, Tsutomu Watanabe, and Mitsuru Iwamura (2007). "Do larger firms have more interfirm relationships?" Physica A: Statistical Mechanics and its Applications, 383(1), 158-163.

Serrano, Ma Ángeles and Marián Boguñá (2003). "Topology of the World Trade Web." Physical Review E, 68, 015101.

Serrano, Ma Ángeles, Marián Boguñá, and Alessandro Vespignani (2007). "Patterns of dominant flows in the world trade web." Journal of Economic Interaction and Coordination, 2(2), 111-124.

Telesford, Qawi K, Karen E Joyce, Satoru Hayasaka, Jonathan H Burdette, and Paul J Laurienti (2011). "The Ubiquity of Small-World Networks." Brain Connectivity, 1(5), 367-375.

Timmer, Marcel P., Erik Dietzenbacher, Bart Los, Robert Stehrer, and Gaaitzen J. de Vries (2015). "An Illustrated User Guide to the World Input-Output Database: the Case of Global Automotive Production." Review of International Economics, 23(3), 575-605.

Wasserman, Stanley and Katherine Faust (1994). Social network analysis: Methods and applications. Cambridge University Press.

Watts, Duncan J. and Steven H. Strogatz (1998). "Collective dynamics of 'small-world' networks." Nature, 393(6684), 440-442.

Zhu, Zhen, Michelangelo Puliga, Federica Cerina, Alessandro Chessa, and Massimo Riccaboni (2015). "Global Value Trees." PLoS ONE, 10(5), 1-17. 


\section{Appendix}

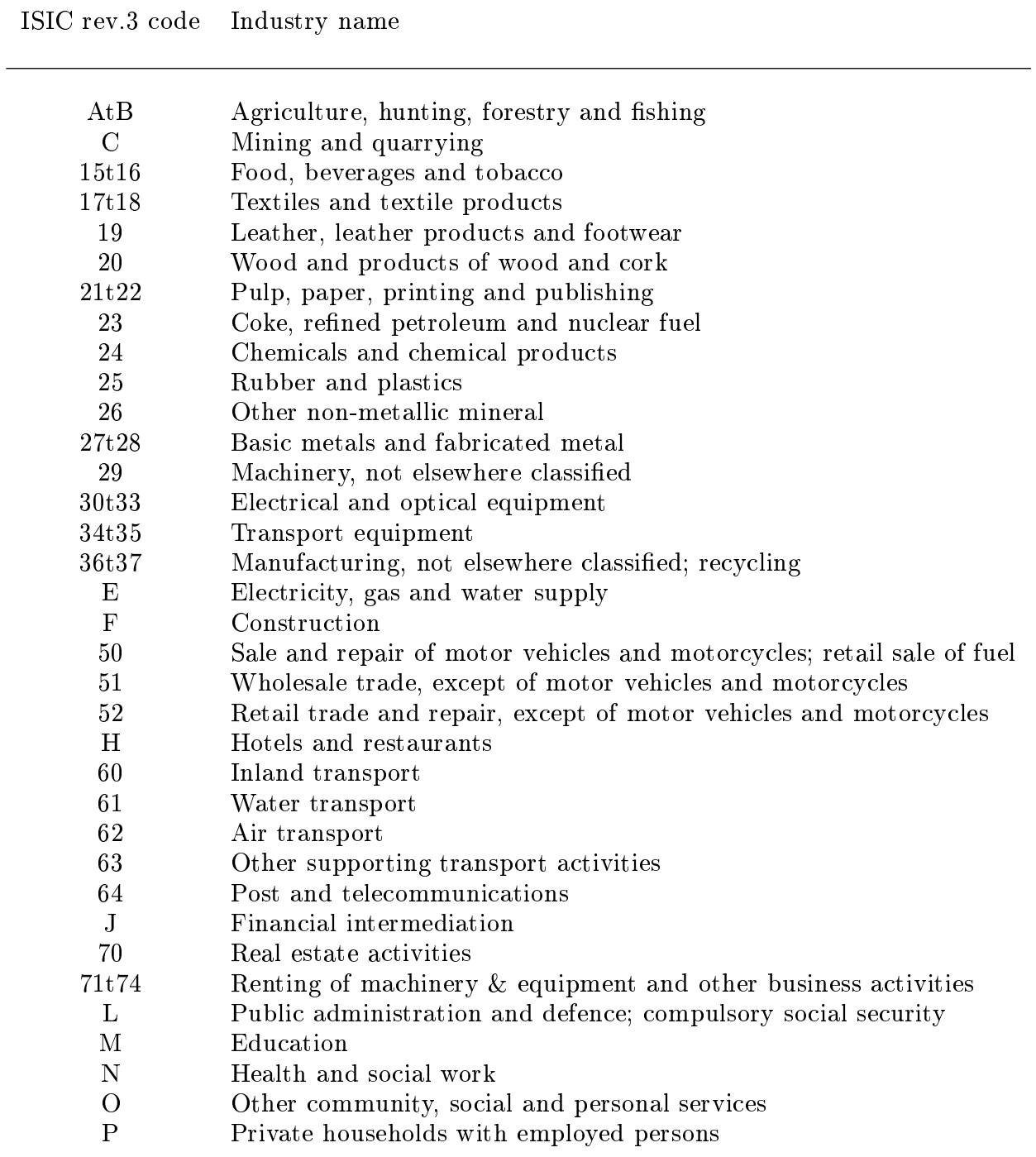

Notes: Throughout this paper, the goods aggregate includes ISIC rev. 3 industry codes from AtB to $\mathrm{F}$ and the services aggregate includes ISIC rev. 3 codes between 50 and P.

TABLE 1. Sectoral breakdown in the World Input-Output Database (WIOD) (35 sectors) 


\begin{tabular}{cl}
\hline ISO alpha-3 codes & Country names \\
& \\
\hline AUS & Australia \\
AUT & Austria \\
BEL & Belgium \\
BGR & Bulgaria \\
BRA & Brazil \\
CAN & Canada \\
CHN & China \\
CYP & Cyprus \\
CZE & Czech Republic \\
DEU & Germany \\
DNK & Denmark \\
ESP & Spain \\
EST & Estonia \\
FIN & Finland \\
FRA & France \\
GBR & United Kingdom \\
GRC & Greece \\
HUN & Hungary \\
IND & India \\
IDN & Indonesia \\
IRL & Ireland \\
ITA & Italy \\
JPN & Japan \\
KOR & South Korea \\
LTU & Lithuania \\
LUX & Luxembourg \\
LVA & Latvia \\
MEX & Mexico \\
MLT & Malta \\
NLD & The Netherlands \\
POL & Poland \\
PRT & Portugal \\
ROM & Romania \\
RUS & Russia \\
SVK & Slovak Republic \\
SVN & Slovenia \\
SWE & Sweden \\
TUR & Turkey \\
TWN & Taiwan \\
USA & United States \\
& \\
\hline &
\end{tabular}

TABle 2. Geographical breakdown in the World Input-Output Database (WIOD) (40 countries) 


\section{WORKING PAPERS}

\section{3}

01|13 Macroeconomic forecasting using lowfrequency filters

João Valle e Azevedo | Ana Pereira

02|13 Everything you always wanted to know about sex discrimination

Ana Rute Cardoso | Paulo Guimarães | Pedro Portugal

03|13 Is there a role for domestic demand pressure on export performance?

Paulo Soares Esteves | António Rua

04|13 Ageing and fiscal sustainability in a small euro area economy

Gabriela Castro | José R. Maria | Ricardo Mourinho Félix | Cláudia Rodrigues Braz

05|13 Mind the gap! The relative wages of immigrants in the Portuguese labour market Sónia Cabral | Cláudia Duarte

06|13 Foreign direct investment and institutional reform: Evidence and an application to Portugal

Paulo Júlio | Ricardo Pinheiro-Alves | José Tavares

07|13 Monetary policy shocks: We got news! Sandra Gomes | Nikolay Iskrev | Caterina Mendicino

08|13 Competition in the Portuguese Economy: Estimated price-cost margins under imperfect labour markets

João Amador | Ana Cristina Soares

09|13 The sources of wage variation: a threeway high-dimensional fixed effects regression model

Sonia Torres | Pedro Portugal | John T. Addison | Paulo Guimarães
10|13 The output effects of (non-separable) government consumption at the zero lower bound

Valerio Ercolani | João Valle e Azevedo

11|13 Fiscal multipliers in a small euro area economy: How big can they get in crisis times?

Gabriela Castro | Ricardo M. Felix | Paulo Julio | Jose R. Maria

12|13 Survey evidence on price and wage rigidities in Portugal

Fernando Martins

13|13 Characterizing economic growth paths based on new structural change tests Nuno Sobreira | Luis C. Nunes | Paulo M. M. Rodrigues

14|13 Catastrophic job destruction Anabela Carneiro | Pedro Portugal | José varejão

$15 \mid 13$ Output effects of a measure of tax shocks based on changes in legislation for Portugal

Manuel Coutinho Pereira | Lara Wemans

16|13 Inside PESSOA - A detailed description of the model

Vanda Almeida | Gabriela Castro | Ricardo M. Félix | Paulo Júlio | José R. Maria

17|13 Macroprudential regulation and macroeconomic activity

Sudipto Karmakar

18|13 Bank capital and lending: An analysis of commercial banks in the United States Sudipto Karmakar | Junghwan Mok 


\section{4}

1|14 Autoregressive augmentation of MIDAS regressions

Cláudia Duarte

2|14 The risk-taking channel of monetary policy - exploring all avenues

Diana Bonfim | Carla Soares

3|14 Global value chains: Surveying drivers, measures and impacts

João Amador | Sónia Cabra

4|14 Has US household deleveraging ended? a model-based estimate of equilibrium debt

Bruno Albuquerque | Ursel Baumann | Georgi Krustev

5|14 The weather effect: estimating the effect of voter turnout on electoral outcomes in italy

Alessandro Sforza

6|14 Persistence in the banking industry: fractional integration and breaks in memory Uwe Hassler | Paulo M.M. Rodrigues | Antonio Rubia

7|14 Financial integration and the great leveraging Daniel Carvalho

8|14 Euro area structural reforms in times of a global crisis

Sandra Gomes

9|14 Labour demand research: towards a better match between better theory and better data

John T. Addison | Pedro Portugal | José Varejão
10|14 Capital inflows and euro area long-term interest rates

Daniel Carvalho | Michael Fidora

11|14 Misallocation and productivity in the lead up to the Eurozone crisis

Daniel A. Dias | Carlos Robalo Marquesz | Christine Richmond

12|14 Global value chains: a view from the euro area

João Amador | Rita Cappariello | Robert Stehrer

13|14 A dynamic quantitative macroeconomic model of bank runs

Elena Mattana | Ettore Panetti

14|14 Fiscal devaluation in the euro area: a model-based analysis

S. Gomes | P. Jacquinot | M. Pisani

15|14 Exports and domestic demand pressure: a dynamic panel data model for the euro area countries

Elena Bobeica | Paulo Soares Esteves | António Rua | Karsten Staehr

16|14 Real-time nowcasting the US output gap: singular spectrum analysis at work Miguel de Carvalho | António Rua 
1|15 Unpleasant debt dynamics: can fiscal consolidations raise debt ratios?

Gabriela Castro | Ricardo M. Félix | Paulo Júlio | José R. Maria

2|15 Macroeconomic forecasting starting from survey nowcasts

João Valle e Azevedo | Inês Gonçalves

3|15 Capital regulation in a macroeconomic model with three layers of default

Laurent Clerc | Alexis Derviz | Caterina Mendicino | Stephane Moyen | Kalin Nikolov | Livio Stracca | Javier Suarez | Alexandros P. Vardoulakis

4|15 Expectation-driven cycles: time-varying effects

Antonello D'Agostino | Caterina Mendicino

5|15 Seriously strengthening the tax-benefit link

Pedro Portugal | Pedro S. Raposo

6|15 Unions and collective bargaining in the wake of the great recession

John T. Addison | Pedro Portugal | Hugo Vilares

7|15 Covariate-augmented unit root tests with mixed-frequency data

Cláudia Duarte

8|15 Financial fragmentation shocks

Gabriela Castro | José R. Maria | Paulo úlio | Ricardo M. Félix

9|15 Central bank interventions, demand for collateral, and sovereign borrowing cost Luís Fonseca | Matteo Crosignani | Miguel Faria-e-Castro
10|15 Income smoothing mechanisms after labor market transitions

Nuno Alves | Carlos Martins

11|15 Decomposing the wage losses of displaced workers: the role of the reallocation of workers into firms and job titles Anabela Carneiro | Pedro Raposo | Pedro Portugal

12|15 Sources of the union wage gap: results from high-dimensional fixed effects regression models

John T. Addison | Pedro Portugal | Hugo Vilares

13|15 Assessing european firms' exports and productivity distributions: the compnet trade module Antoine Berthou | Emmanuel Dhyne | Matteo Bugamelli | Ana-Maria Cazacu | Calin-Vlad Demian | Peter Harasztosi | Tibor Lalinsky | Jaanika Meriküll | Filippo Oropallo | Ana Cristina Soares

14|15 A new regression-based tail index estimator: an application to exchange rates

João Nicolau | Paulo M. M. Rodrigues

15|15 The effect of bank shocks on firm-level and aggregate investment João Amador | Arne J. Nagengast

16|15 Networks of value added trade João Amador | Sónia Cabral 


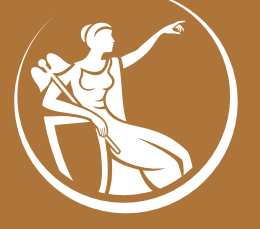

